\title{
Referral Pattern and Haematological Disorders in a Tertiary Hospital
}

\author{
Onoja, AM ${ }^{1}$ Nwannadi, AI Onoja, AT Aba, IH Jatau, Es Osho, PO Alao, OO Ogli, $S^{5}$ \\ ${ }^{\prime}$ Department of Haematology, College of Health Sciences, Benue State University/Teaching Hospital, Makurdi, Nigeria. \\ ${ }^{2}$ Department of Medical Microbiology, University of Agriculture, Makurdi, Nigeria. \\ ${ }^{3}$ Department of Haematology and Blood Transfusion, College of Health Sciences/ Jos University Teaching Hospital, Jos Nigeria. \\ ${ }^{4}$ Department of Haematology and blood Transfusion, University of Medical Sciences, Ondo-city, Nigeria. \\ ${ }^{5}$ Department of Physiology, College of Health Sciences, Benue State University, Makurdi, Nigeria.
}

*Correspondence: Dr. Michael Anthony ONOJA

Email:doctoronoja@yahoo.com

$\begin{array}{ll}\text { Article information } & \\ \text { Date Submitted: } & 14 / 3 / 2021 \\ \text { Date Accepted: } & 23 / 3 / 2021\end{array}$

\section{ABSTRACT}

This study aimed to determine the pattern of referrals and haematological disorders at Benue State University Teaching Hospital. This was a retrospective study of records of a total of 222 adults and Paediatric patients suspected to have haematological disorders, seen and referred from different clinics and wards within and outside the study facility to the Haematologists for evaluation between June 2012 to July 2019 inclusive. These patients were clerked by the Haematologists, peripheral blood samples were taken for full blood count, red cell indices, reticulocyte count and peripheral blood film examination. Bone Marrow Aspiration was done on all the patients and the slides examined. Where indicated, further flowcytometry was done for complete diagnosis. Of the 222 referred, $127(57.2 \%)$ were males while $95(42.8 \%)$ were females, with M:F ratio of 1.3:1. The age range of patients was 3 to 95 years with median age of 36.5 years. Those in the age group of 16-35 years constituted the majority $81(36.5 \%)$, while the least $5(2.3 \%)$ referred cases were in the age group of 76 years and above. The highest referral to the Haematologists was 40(18\%) in 2015 and 2018 each, while the least 14(6.3\%) was in 2012. The bulk of referrals to the Haematologist was from Medicine 103(46.4\%), followed by referrals from General Outpatient Department (GOPD) 29(13.1\%) and then Paediatrics 27(12.2\%), the least was from Ear Nose and Throat (ENT). The main indication for referral was Unexplained Anaemia 68(30.6\%), followed by Splenomegaly 26(11.7\%). One hundred and eighty $(81.1 \%)$ of the total referred cases had at least an established haematological disorder. The most common haematological disorder established from the total referred cases was Combined Iron Deficiency Anaemia and Megaloblastic Anaemia (IDA/MA) 52(23.4\%). This was followed by Chronic Lymphocytic Leukaemia (CLL) 23(10.4\%). In conclusion, referrals from other physicians to the Haematologists have very high likelihood of haematological disorder. We recommend that attending Haematologists treat all referred cases with very high index of suspicion so as not to miss a potentially life threatening haematological disorder.

Keywords: Pattern, Referral, Haematology, Disorders.

\section{How to cite this article}

Onoja, AM Nwannadi, AI Onoja, AT Aba, IH Jatau, E Osho, PO et al., Referral Pattern and Haematological Disorders in a Tertiary Hospital. J Biomed Res Clin Pract:2021;4(1):61-69. doi.org/10.46912/jbrcp.190

\section{Access to the article}

website: http://www.jbrcp.net : https://doi.org/10.46912/jbrcp.190 


\section{INTRODUCTION}

A good referral system helps to keep track of patients throughout the care continuum. The main goal of referral is to streamline communication among primary care physicians, specialists, and the patient's healthcare provider. Ultimately, the aim will be to enhance the overall quality of patient's care by improving transparency, limiting operational inefficiencies, costeffective use of health services and improving existing processes of the healthcare facility.

Haematology Departments, particularly those in young tertiary hospitals like ours, may have unique patients' demographics from multiple referral sources. The appropriateness and the Haematologic indications for such referrals may vary among physicians and from one facility to another.

There has been emerging reports of increasing cases of haematological disorders which may be indicative of improved diagnostic and detective techniques ${ }^{1}$ and the global increase of non-communicable diseases, ${ }^{2}$ Literature search revealed dearth of information and data on the pattern of referrals to the Haeamtologist and on the pattern of haematological disorders in the center. This study therefore aimed to determine the pattern of referrals and haematological disorders at a Haematology Unit of Benue State University Teaching Hospital, Makurdi, Benue State Nigeria. The specific objectives were sources of the referrals, indications for the referrals, the type/commonest haematological disorders established and the relevant biographical details.

\section{MATERIALS AND METHODS}

The study was conducted in the Haematology Department of Benue State University Teaching Hospital, Makurdi, Nigeria from June 2012 to July 2019. Benue State is a state in the middle belt region of Nigeria with a total population of $5,840,420$ which is a projection from 2006 population census ${ }^{3,4}$. The hospital is a relatively young tertiary healthcare center founded in the year 2006 with about 1500 beds. It Serves the entire State and some other neighboring states within the region. The states include Nasarawa, Taraba, part of Cross River and Kogi. The Haematology Department of the hospital was established in January 2012 which now has five (5) Consultant Haematologists. One Professor, two Associate Professors and one Senior Lecturer.

This was a retrospective study of records of a total of 222 adults and Paediatric patients suspected to have haematological disorders, seen and referred from different clinics and wards within and outside the study facility to the Haematologists for evaluation between June 2012 to July 2019 inclusive. These patients were clerked by the Haematologists, peripheral blood samples were taken for full blood count, red cell indices, reticulocyte count and peripheral blood film examination. Bone Marrow Aspiration was done on all the patients and the slides examined. Where indicated, further flowcytometry was done for complete diagnosis. Those excluded from this study were patients already diagnosed with haematological disorder, those on treatment for a haematological disorder and those on routine Haematology Out-Patient Clinic (HOPC) visits.

\section{Data analysis}

The data obtained were fed into IBM SPSS Statistics for Windows, version 20 (Armonk. NY: IBM Corp) for analysis using Simple frequencies and crosstabulations. Chi-squared test was used to check for associations between two categorical variables. A Pvalue less than 0.05 was considered statistically significant. The final results were presented in figures and tables.

\section{RESULTS}

Of the 222 suspected cases referred, 127 (57.2\%) were males while 95(42.8\%) were females (Table 1), with 
M:F ratio of about 1.3:1. The age range of the studied population was 3 to 95 years with the median age of 36.5 years. Those in the age group of 16-35 years constituted the majority $81(36.5 \%)$, while the least $5(2.3 \%)$ referred cases were in the age group of 76 years and above (Table 1). The highest referrals $40(18 \%)$ to the Haematologist were in 2015 and 2018 each, while the least 14(6.3\%) was in 2012 (Figure I). The bulk of referrals to the Haematologist was from Medicine 103(46.4\%), this was followed by referrals from GOPD 29(13.1\%) and then Paediatrics 27(12.2\%), the least was from ENT (Table 2). The main indication for the referral was Unexplained Anaemia 68(30.6\%), followed by Splenomegaly 26(11.7) (Figure 2). One hundred and

Table 1: Sex, Age and Disorders among the referred cases within the Seven (7) year period

\begin{tabular}{|c|c|c|c|c|c|c|c|c|c|c|}
\hline & & \multicolumn{8}{|c|}{ June 2012 to July 2019} & \multirow{2}{*}{$\begin{array}{l}\text { Total } \\
\text { n(\%) }\end{array}$} \\
\hline & & 2012 & 2013 & 2014 & 2015 & 2016 & 2017 & 2018 & 2019 & \\
\hline \multirow[t]{2}{*}{ Sex } & $\mathrm{F}$ & 7 & 4 & 7 & 16 & 16 & 20 & 19 & 6 & $95(42.8)$ \\
\hline & M & 7 & 12 & 20 & 24 & 13 & 15 & 21 & 15 & 127(57.2) \\
\hline \multicolumn{2}{|l|}{ Total } & 14 & 16 & 27 & 40 & 29 & 35 & 40 & 21 & $222(100.0)$ \\
\hline \multirow{5}{*}{ Age Group } & under 15 & 0 & 3 & 5 & 4 & 3 & 2 & 6 & 4 & 27(12.2) \\
\hline & $16-35$ & 7 & 5 & 7 & 14 & 11 & 12 & 19 & 6 & $81(36.5)$ \\
\hline & $36-55$ & 4 & 5 & 7 & 14 & 8 & 13 & 3 & 3 & $57(25.7)$ \\
\hline & $56-75$ & 3 & 3 & 8 & 6 & 7 & 8 & 11 & 6 & $52(23.4)$ \\
\hline & 76 and over & 0 & 0 & 0 & 2 & 0 & 0 & 1 & 2 & $5(2.3)$ \\
\hline Total & & 14 & 16 & 27 & 40 & 29 & 35 & 40 & 21 & $222(100.0)$ \\
\hline \multirow{2}{*}{ Disorders } & Non-Haematological & 4 & 1 & 4 & 6 & 6 & 5 & 11 & 5 & $42(18.9)$ \\
\hline & Haematological & 10 & 15 & 23 & 34 & 23 & 30 & 29 & 16 & $180(81.1)$ \\
\hline Total & & 14 & 16 & 27 & 40 & 29 & 35 & 40 & 21 & $222(100.0)$ \\
\hline
\end{tabular}

Table 2: Types of Disorder and Sources of Referral to the Haematologist

\begin{tabular}{|c|c|c|c|c|c|}
\hline & & \multicolumn{2}{|c|}{ Disorders } & \multirow{2}{*}{$\begin{array}{l}\text { Total } \\
\text { n(\%) }\end{array}$} & \\
\hline & & Non-Haematological & Haematological & & \\
\hline \multirow{9}{*}{ Sources of Referral } & $\mathrm{A} / \mathrm{E}$ & 5 & 8 & $13(5.9)$ & \multirow{9}{*}{$P=.324$} \\
\hline & ENT & 0 & 3 & $3(1.4)$ & \\
\hline & External sources & 3 & 15 & $18(8.1)$ & \\
\hline & GOPD & 3 & 26 & $29(13.1)$ & \\
\hline & Medicine & 20 & 83 & $103(46.4)$ & \\
\hline & $\mathrm{O} / \mathrm{G}$ & 2 & 9 & $11(5.0)$ & \\
\hline & Ophthalmology & 2 & 2 & $4(1.8)$ & \\
\hline & Paediatrics & 5 & 22 & $27(12.2)$ & \\
\hline & Surgery & 2 & 12 & $14(6.3)$ & \\
\hline Total & & $42(18.9)$ & $180(81.1)$ & $222(100.0)$ & \\
\hline
\end{tabular}

* Linear-by-Linear Association, Value $=253, d f=1$, No significant relationship between the sources of referral and the the Disorders (appropriateness of the referral) $(P=.324)$

Keys:

A/E: Accident/Emergency; ENT: Ear Nose and Throat; GOPD: General Outpatient Department;

$\boldsymbol{O} / \boldsymbol{G}$ : Obstetrics and Gynaecology 
eighty (81.1\%) of the total referred cases had different types of haematological disorders while the rest of 42(18.9) referred cases had no haematological disorder (Table 1).

The most common haematological disorder from the total referred cases was Combined Iron Deficiency Anaemia and Megaloblastic Anaemia (IDA/MA) 52(23.4\%). This was followed by Chronic Lymphocytic Leukaemia (CLL) 23(10.4\%) (Figure 3).

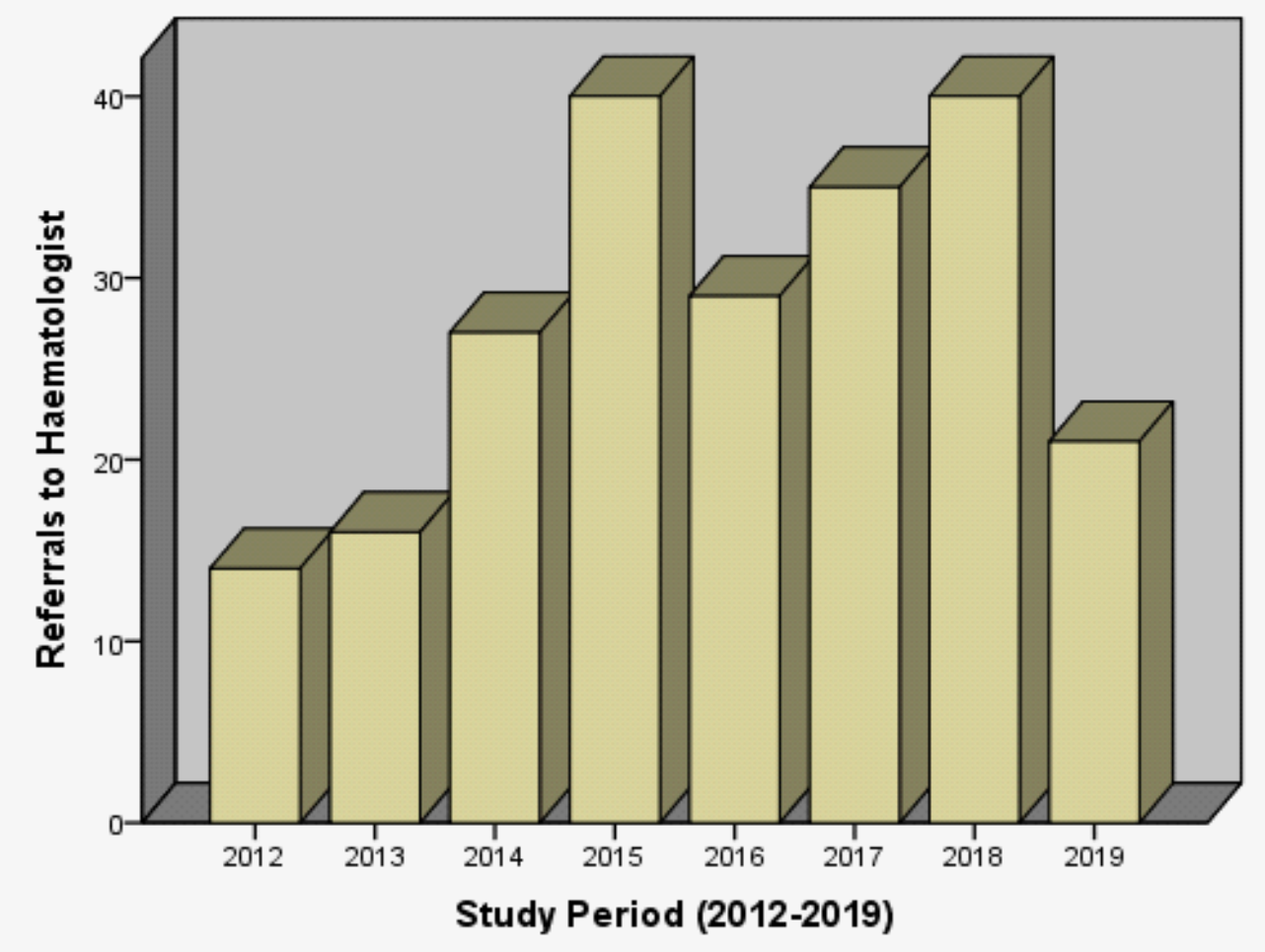

Figure 1: All referrals to the Haematologist from June 2012 to July 2019 


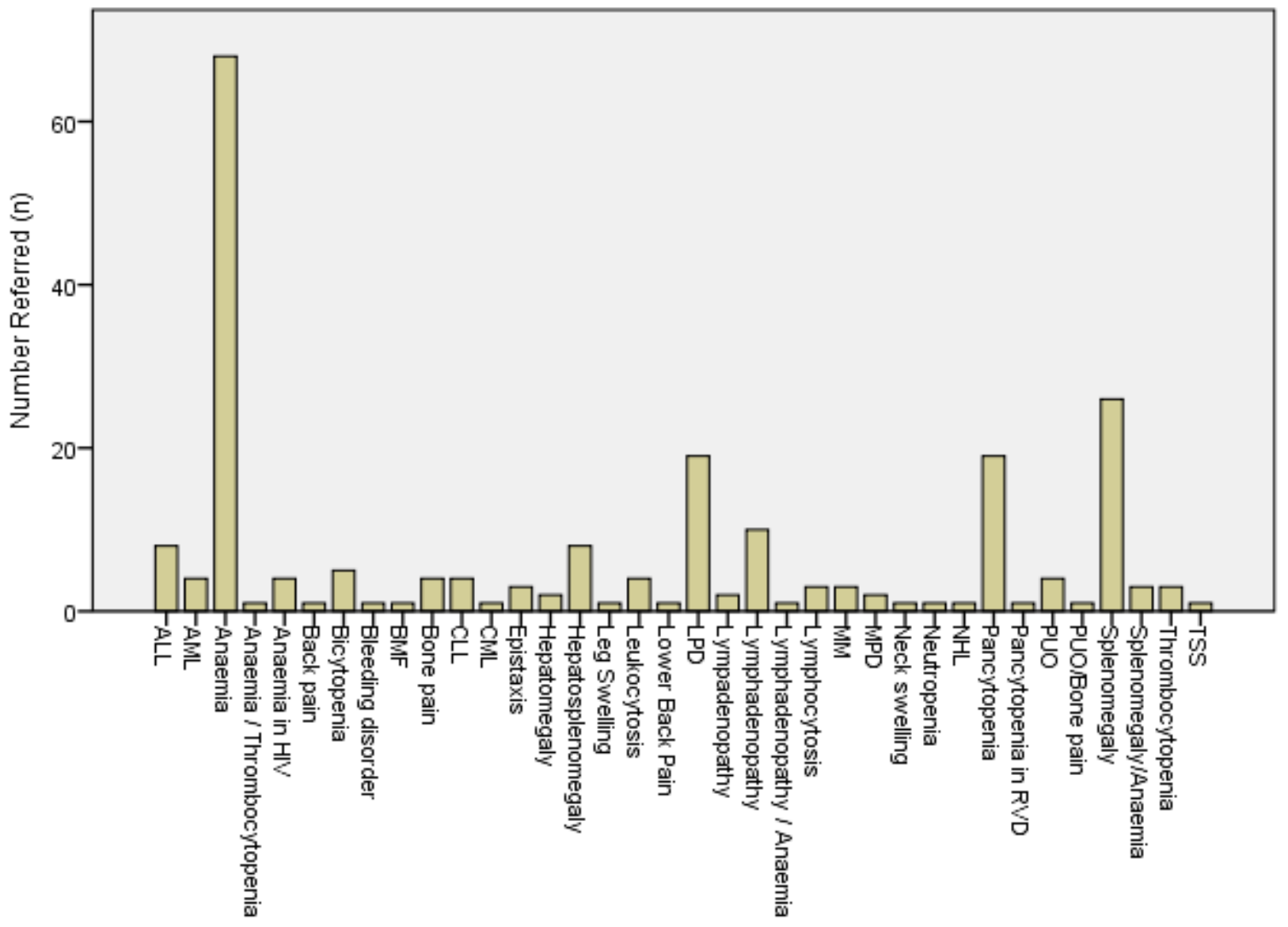

Figure 2: Clinical and Laboratory Indications for Referrals to the Haematologist

Keys:

ALL: Acute Lymphoblastic Leukaemia; AML: Acute Myeloblastic Leukaemia; BMF: Bone Marrow Failure; CLL: Chronic Lymphocytic Leukaemia; CML: Chronic Myeloid Leukaemia; LPD: Lymphoproliferative Disorder; MM: Multiple Myeloma; MPD: Myeloproliferative Disorder; NHL: Non-Hodgkin's Lymphoma; PUO: Pyrexia of Unknown Origin; TSS: Tropical Splenomegaly Syndrome. 


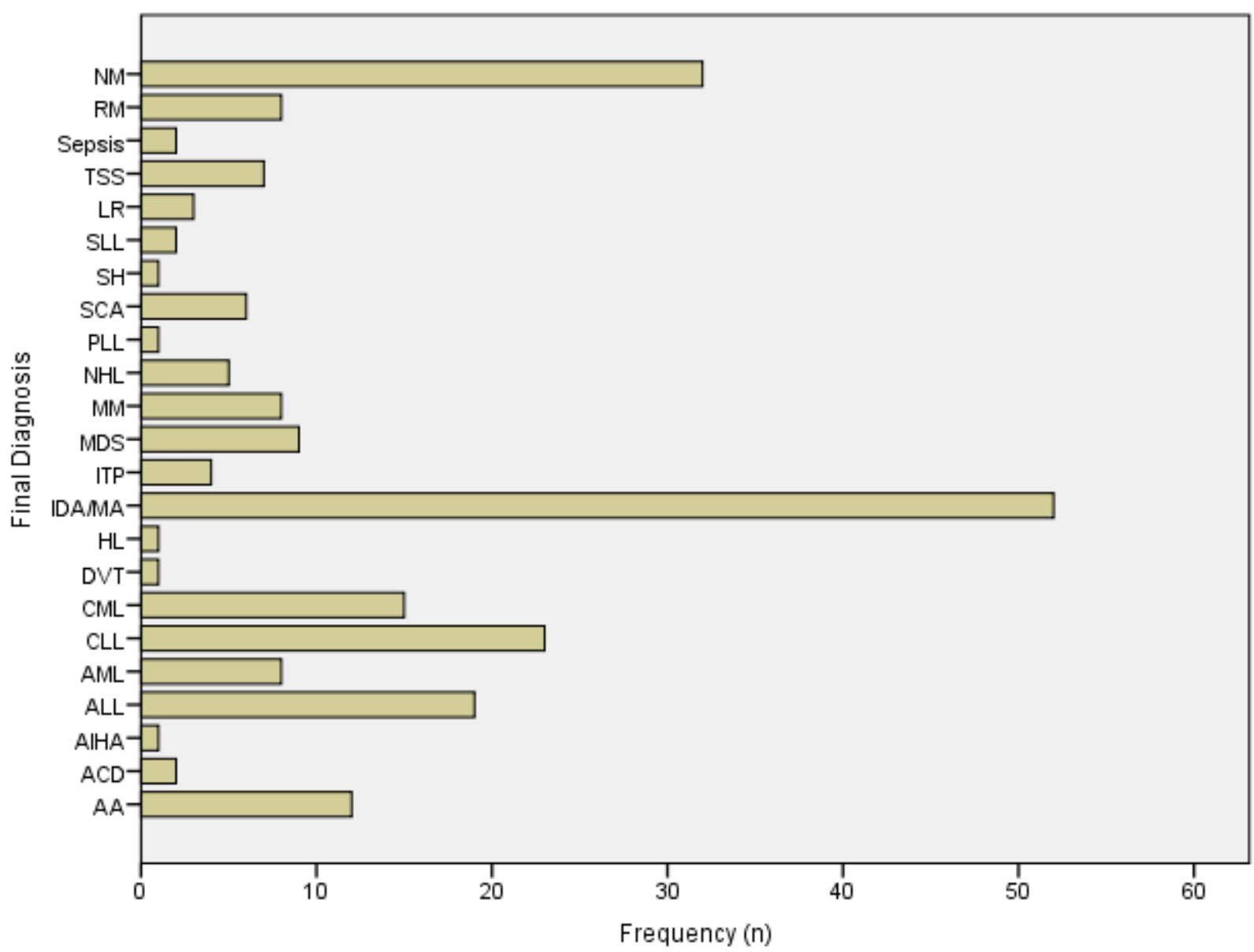

Figure 3: The Final Diagnosis of the Referred cases

Keys:

AA: Aplastic Anaemia; ACD: Anaemia of Chronic Disorder; AIHA: Autoimmune Haemolytic Anaemia;

ALL: Acute Lymphoblastic Leukaemia; AML: Acute Myeloblastic Leukaemia; BMF: Bone Marrow Failure;

CLL: Chronic Lymphocytic Leukaemia; CML: Chronic Myeloid Leukaemia; DVT: Deep Vein Thrombosis;

HL: Hodgkin's Lymphoma; IDA/MA: Iron Deficiency Anaemia/Megaloblastic Anaemia;

ITP: Idiopathic Thrombocytopenic Purpura; MDS: Myelodysplastic Syndrome; MM: Multiple Myeloma;

NHL: Non-Hodgkin's Lymphoma; PLL: Prolymphocytic Leukaemia; SCA: Sickle Cell Anaemia; SH: Sinus Histocytosis;

SLL: Small Lymphocytic Lymphoma; LR: Leukaemoid Reaction; TSS: Tropical Splenomegaly Syndrome; RM: Reactive Marrow;

NM: Normal Marrow. 


\section{DISCUSSION}

One hundred and eighty percent $(81.1 \%)$ of suspected cases referred by the physicians to the Haematologists in this study had one form of haematological disorder or the other. This was an indication of the appropriateness of referrals when it is from a physician and by implication signifies a very high likelihood of haematological disorder. Similar studies elsewhere agreed with our finding. Ninety-one per cent (91\%) of referred cases in a study by Wright et al., had an abnormality ${ }^{5}$

The bulk of referral to Haematologist in this study was from Internal Medicine. This was followed by Primary Care Physician (GOPD) and then from Paediatrics. Little is actually known about the rate of referrals for suspected haematologic disorders to the Haematologist generally. The presenting features of a number of haematological disorders are often non-specific and may, at onset, be mistaken for purely medical disorder, accounting for the higher referrals from Internal Medicine Physician to the Haematologist. This may also explain the observed rate of referrals from the Pediatricians coupled with the fact that Haematologic malignancies ${ }^{1}$ and anaemias ${ }^{6}$ have been reported to be among the most common childhood disorders. The Primary Care Physician (PCP) who often serves as the first point of contact for most patients, serves a vital role in symptom detection, facilitating diagnoses, treatment and referrals to Specialists. This may explain why PCP accounted for the second highest referrals to the Haematologist in our study. ${ }^{7,8}$

A very high percentage of the referrals from all the specialties to the Haematologist in our study appeared appropriate as they had haematological pathology, however there was no significant relationship between the source of the referrals and the established disorder i.e the appropriateness of the referral (Table 2). Though this study did not evaluate the appropriateness or inappropriateness of these referrals on the basis of individual specialty, we have however cited a few studies that reported high rate of inappropriate referrals from Primary Care Physicians to the Hematologist as these suspected cases had no hematological pathologies. ${ }^{7,9}$ In contrast another survey reported that patients who, for example, presented to primary care clinicians with a new occurrence of moderate to severe thrombocytopenia were appropriately referred to a haematologist. $^{10,11}$ The quality of referrals to the Haematologist from different physicians may therefore be influenced by a number of factors. These factors may range from the specialty to the level of experience and the individual physician's knowledge of Haematology. ${ }^{12,13,14}$

The main indication for the referral was Unexplained Anaemia, followed by Splenomegaly. This agrees with other reports in which an analytical alteration was reported to be the main reason for referring patients. ${ }^{7,15}$

The most common haematological disorder from the total referred cases was Combined Iron Deficiency Anaemia and Megaloblastic Anaemia (IDA/MA) $52(23.4 \%)$. This finding is similar to that of Niyaz et $a l,{ }^{16}$ Srinagar, India. Here Iron deficiency anaemia was also the most common haematological disorder accounting for $61 \%$.

In our study, Chronic Lymphocytic Leukaemia accounted for the second most common haematologic disorder. A study by Nwannadi et $\mathrm{al}^{17}$, reported CLL as the most common form of leukaemia found in adults in Western countries and in Nigeria. ${ }^{18}$ In the study by Niyaz et al, while leukaemia, just like ours, was the second most common, theirs however was an acute leukaemia. This observed difference with chronic and acute leukaemias in our study and that of Niyaz et al, respectively, may be explained by the variable spectrum and pattern of haematological disorders in the developing conutries, ${ }^{19,20}$ which therefore underscores the importance of establishing the local pattern of haematological disorders.

\section{CONCLUSION}

In conclusion, referrals from other physicians to the Haematologists have very high likelihood of 
haematological disorder. The bulk of referrals to Haematologists was from Medicine followed closely by GOPD and then Paediatrics. The main indications for the referrals were unexplained Anaemia and Splenomegaly. The most common haematological disorders in the total referred cases were Combined Iron Deficiency Anaemia /Megaloblastic Anaemia and Chronic Lymphocytic Leukaemia.

\section{Recommendation}

We recommend that attending Haematologists treat all referred cases with very high index of suspicion so as not to miss a potentially life threatening haematological disorder.

Conflict of interests: None to declare

\section{REFERENCES}

1. Jatau E, Joseph D, Egesie J, Damulak O, Piwuna T, Onoja A, et al. Acute Lymphoblastic Leukaemia: A Case Report of Long-term Disease-free Survival in a Resource Limited Setting. J Biomed Res Clin Pract. 2020;3(4):457-62. doi.org/10.46912/jbrcp. 182

2. Farhana DT, Nahar Q, Choudhury S. Pattern of Haematological Disorders in a Tertiary Diabetic Hospital: A Pilot Study. J Bangladesh Coll Physicians Surg. 1970;27(3):148-54.

3. DSO, . FKK, . DPD, . TIK, . FU, TTG. Intensification Of Arable Agricultural Land Use As A Response To Changing Agro-Ecological Context In The Benue Basin, Nigeria. Adv Soc Sci Res J. 2019;6(2):400-19.

4. Federal Republic of Nigeria. Legal notice on publication of 2006 census final results. Off Gaz. 2009;96(2):1-42.

5. Give Celso, Ndima Sozinho, Steege Rosalind, Ormel Hermen McCollum, Rosalind Theobald, Sal Taegtmeyer, Miriam Kok, Maryse Sidat, Mohsin. Strengthening referral systems in community health programs: A qualitative study in two rural districts of
Maputo Province, Mozambique. Health Trends. 2019; 19(1):1-11.

6. Jude A, Donatus M. Anaemia of Chronic Disease : An In-Depth Review. 2017;1-9.

7. Uranga Aguirregomezcorta A, Zeberio Etxetxipia I, Furundarena Salsamendi JR, Gonzalez Gonzalez C, Uresandi Iruin N, Arrue Izagirre L, et al. Primary care and hematology department: referral and management guidelines. Int $\mathrm{J}$ Integr Care. 2019;19(4):330.

8. Barnett Michael L, Keating Nancy L. Christakis Nicholas A, O'Malley A. James, Landon Bruce E. Reasons for choice of referral physician among primary care and specialist physicians. Journal of General Internal Medicine. 2012 :27(5):506-512

9. Jenkins RM. Quality of general practitioner referrals to outpatient departments: Assessment by specialists and a general practitioner. $\mathrm{Br} \mathrm{J}$ Gen Pract. 1993;43(368):111-3.

10. Terrell DR, Beebe LA, George JN, Vesely SK, Mold JW. Referral of patients with thrombocytopenia from primary care clinicians to hematologists. Blood. 2009;113(17):4126-7.

11. Wright D, Smith G, Norfolk D, Child A. Sources and types of referral to a haematology department., Health trends. 1992; 24:145-8.

12. El-Jawahri A, Nelson AM, Gray TF, Lee SJ, LeBlanc TW. Palliative and end-of-life care for patients with hematologic malignancies. J Clin Oncol. 2020;38(9):944-53.

13. Daramola OE, Adesina CT, Akande TM. Referral Services under the National Health Insurance Scheme ; a Hospital-Based Descriptive CrossSectional Study in Abuja, Nigeria. World J Innov Res (WJIR. 2019;(2):134-8.

14. Tzartzas K, Oberhauser PN, Marion-Veyron R, Bourquin C, Senn N, Stiefel F. General practitioners referring patients to specialists in tertiary healthcare: A qualitative study. BMC Fam Pract. 2019;20(1):1-9.

15. Howell DA, Smith AG, Jack A, Patmore R, Macleod 
U, Mironska E, et al. Time-to-diagnosis and symptoms of myeloma, lymphomas and leukaemias: A report from the Haematological malignancy Research Network. BMC Hematol. 2013;13(1):9.

16. Niyaz I, Tasleem RA, Bashir H, Bhat N. Research Article Pattern of Hematological Disorders on Bone Marrow Examination : A Study Of 130 Cases Dr. Neelofar Gul, Dr . Bilal Musharaf Banday and Dr . Samina Kanday. 2015:3-6.

17. Nwannadi IA, Mke A, Onoja AM. Epidemiology and Clinical Profile of Patients with Chronic Lymphocytic Leukaemia in a Tertiary Hospital in Nigeria. J Res Basic Clin Sci. 2019;1(1):36-40.

18. Nwannadi A, Olusayo A, Bazuaye GN, Halim NKD, Omoti CE. The epidemiology of haematological malignancies at the university of benin teaching hospital: A ten-year retrospective study. Internet J Epidemiol. 2010;9(2).

19. Young NS, Abkowitz JL, Luzzatto L. New Insights into the Pathophysiology of Acquired Cytopenias. Hematology. 2000;2000(1):18-38.

20. Muzzin LJ. Understanding the Process of Medical Referral: Part 1: Critique of the literature. Can Fam Physician. 1991;37:2155-61. 